\title{
A fast-response production-inventory model for deteriorating seasonal products with learning in set-ups
}

\author{
Ibraheem Abdul* and Atsuo Murata
}

Department of Intelligent Mechanical Systems Engineering, Graduate School of Natural Science and Technology, Okayama University, 3-1-1, Tsushimanaka, Okayama 700-8530, Japan.

\begin{tabular}{|c|c|}
\hline A R T I C L E I N F O & A B S T R A T T \\
\hline $\begin{array}{l}\text { Article history: } \\
\text { Received } 1 \text { June } 2010 \\
\text { Received in revised form } \\
\text { June, } 29,2011 \\
\text { Accepted } 1 \text { July } 2011 \\
\text { Available online } \\
2 \text { July } 2011 \\
\text { Keywords: } \\
\text { Production } \\
\text { Learning } \\
\text { Set-up reduction } \\
\text { Seasonal products } \\
\text { Deterioration } \\
\text { Varying demand pattern }\end{array}$ & $\begin{array}{l}\text { The classical production-inventory model assumes that both demand and set-up costs are } \\
\text { constant. However, in real manufacturing environment, managers usually embark on } \\
\text { continuous improvement programmes that often lead to more effective use of tools and } \\
\text { machineries and consequently reduction in set-up costs. In fact, constant emphasis on reduction } \\
\text { of set-up costs is usually cited as one of the factors responsible for the efficiency of Japanese } \\
\text { manufacturing methods. On the other hand, the demand for seasonal product is often } \\
\text { characterized by a mixture of time-dependent patterns over the entire season. This paper } \\
\text { investigates the effect of learning-based reduction in set-up costs on the optimal schedules and } \\
\text { costs of a production-inventory system for deteriorating seasonal products. The demand pattern } \\
\text { is a general three-phase ramp-type demand function that represents the various phases of } \\
\text { demand commonly observed in many seasonal products in the market. A two-parameter } \\
\text { Weibull-distribution function is used for the deterioration of items in order to make the model } \\
\text { more generalized and realistic. The study further presents two different multi-period production } \\
\text { strategies that can ensure a fast-response to customers' demand and compare them with the } \\
\text { usual single period strategy. The Numerical example and sensitivity analysis shows that } \\
\text { learning-based reduction in set-up costs leads to higher production frequency and shorter } \\
\text { production runs which are vital aspects of the just-in-time (JIT) philosophy. }\end{array}$ \\
\hline
\end{tabular}

\section{Introduction}

Seasonal items like fruits, fish, winter cosmetics, fashion apparel, etc. generally exhibits different demand patterns at various times during the season. The demand usually begins with increasing trend, attains a peak and becomes steady at the middle of the season. Various time-dependent functions have been used to depict this demand pattern. These include time dependent quadratic function, ramp-type function etc. This study focuses on seasonal items that deteriorate during inventory. The combination of demand fluctuation and deterioration makes it highly risky to adopt a single production lot strategy to satisfy customers' demand for the entire season. Small lots, short-run and high-speed multi-period production strategy will enable a fast-response to customers' demand and reduce likely loss due to deterioration for this class of products. According to Şen (2008), successful implementation of a quick-response system will require substantial information sharing between the manufacturer and the retailer. It will also require a just-in-time shipping policy with frequent, small lots and flexible manufacturing with short-run and high-speed processing. Jaber and Bonney (2003)

* Corresponding author Tel.: +81-90-6418-0253; fax: +81-86-251-8056

E-mail: dotun.abdul@gmail.com (I. Abdul) 
observed that producing smaller lots and increasing frequency of production are encouraged by the incorporation of the effects of learning in set-ups into optimal lot sizing. Thus, this paper incorporates the effects of learning in set-ups into a multi-period production-inventory model for deteriorating seasonal products.

In production inventory models, the set-up cost represents the cost incurred whenever a production run is being prepared/set up and usually includes the labour set-up cost, cost of materials used during set-up testing, cost of time during which production cannot take place during set-up, cost of inspection of equipment before production, etc. The numerous benefits of reducing this cost have been identified as follows: improved quality control, flexibility, increased effective capacity and reduced inventory related operating costs (Porteus, 1985). Constant emphasis on reduction of set-up costs has also been cited as one of the factors responsible for the efficiency of Japanese manufacturing methods (Rachamadugu \& Schriber, 1995). Several research efforts have addressed set-up cost reduction and its techniques (e.g. Schonberger, 1982; Porteus, 1985; Chand, 1989; Paknejad et al., 1996; Andijani, 1998; Jaber \& Bonney, 2003; Darwish, 2008). Set-up time/cost reduction can be achieved through emphasis on learning effects, continuous system improvement, and incremental process improvement (Rachamadugu \& Schriber 1995).

It is a common experience in real life that a worker engaged in repetitive operations improves with time due to learning effects. The learning phenomenon implies that the performance of a system improves with time because the firms and employees perform the same task repeatedly and consequently learn how to provide a standard and improved level of performance. In manufacturing environment, factors that contribute to this improvement may include the more effective use of tools and machines, increased familiarity with operational tasks and work environment, and enhanced management efficiency (Jaber \& Bonney, 1999). Since the pioneering work of Wright (1936) on learning effects in repetitive task, several researchers have studied the effect of learning in optimal lot sizing problems. Some of these studies focused attention on the effect of learning on production rate/cost when the set-up cost is constant (e.g. Keachie \& Fontana, 1966; Steedman, 1970; Adler \& Nander, 1974; Fisk \& Ballou, 1982; Salameh, et al. 1993; Jaber \& Bonney, 1997; Jaber \& Sikström 2004). Some other studies considered the effect of learning in set-up costs/time (e.g. Karwan et al., 1988; Reploge, 1988; Chand 1989; Cheng, 1994). Detailed review of literatures on effect of learning in optimal lot sizing problem can be found in the works of Gulledge and Khoshnevis (1987) and Jaber and Bonney (1999).

Some recent models recognized the effect of learning on more than one aspect of the productioninventory system. Jaber and Bonney (2003) investigated the effects of learning and forgetting on setups and product quality while Jaber et al. (2010) presented a joint replenishment inventory model for a three-stage (supplier-manufacturer-retailer) decentralized supply chain with the manufacturer encountering learning and forgetting effects in set-ups, production, and product quality. Jaber and El Saadany (2011) extended the work of Dobos and Richter $(2003,2004)$ to include the effects of learning in production and remanufacturing processes. All the above models assumed demand to be constant and no deterioration of items in inventory. However for most seasonal products, the demand is time varying and products also deteriorates with time.

Chiu et al. (2003) studied the deterministic time-varying demand lot-sizing problem which incorporates the effects of learning and forgetting in set-ups and production simultaneously. Balkhi (2003) developed a general production lot size model for deteriorating items whose production is subjected to full transmission of learning. The model allowed production, demand and deterioration rates to vary with time and shortages were allowed with partial backlogging of demand. Alamri and Balkhi (2007) generalized the model of Jaber and Bonney (1996) by presenting general learn-forget curve model in which demand and product deterioration rates are arbitrary functions of time. The 
effect of learning in set-up and the possibility of variation in demand patterns within a given period were, however, not considered in the model.

For most seasonal products, the demand variation is often a mixture of non-decreasing, constant and non-increasing functions of time. The demand for this class of products increases with time at the beginning of its season. It attains a peak and becomes steady at the middle of the season and it finally decreases when the time reaches to the end of the season. The optimal production strategy for this type of goods may vary with a given set of system parameters due to possibility of variation in demand patterns within a given period unlike that of products with unidirectional demand pattern. Hill (1995) developed the first model for products whose demand variation is a combination of two different types of demand in two successive periods over the entire time horizon and termed it as a ramp-type demand pattern. Subsequently, many researchers have adopted this pattern for seasonal products whose demand is a mixture of non-decreasing, constant and non-increasing functions of time.

Panda et al. (2008) developed an inventory model for deteriorating seasonal products using ramp-type demand pattern with a three-phase variation in demand. The demand pattern in this case is assumed to increase exponentially with respect to time up to a certain point. Then it becomes steady and finally decreases exponentially and becomes asymptotic. Another form of this pattern was used by Cheng and Wang (2009), in developing an economic order quantity model for deteriorating items. Production inventory models for seasonal products using a ramp-type demand pattern in recent time includes Manna and Chaudhuri (2006), Panda et al. (2009), Manna and Chiang (2010). The production inventory models are, however, single period models and did not allow for the reduction in set-up costs. Also none of these models for seasonal products consider the effects of learning on set-up and the need to respond quickly to customer demand as they arise during the season.

This paper fill these gaps by considering the multi-period production lot sizing problem that involves deteriorating seasonal product whose demand is a mixture of non-decreasing, constant and nonincreasing functions of time. The study incorporates the effect of learning in reducing set-up cost and considers various production strategies that can ensure a fast-response to customers' demand. The demand pattern is a general three-phase ramp-type demand function that represents the various phases of demand commonly observed in many seasonal products in the market. A two-parameter Weibulldistribution function is used for the deterioration of items in order to make the model more generalized and realistic.

\section{Learning in set-up}

The simplest and most commonly used learning theory in lot-sizing models is the one introduced by Wright (1936) which links the performance of a specific task to the number of times that task is repeated. Wright (1936) used a power function formulation to obtain a learning curve which is of the form $T_{n}=T_{1} n^{-b}$ where $T_{n}$ is the time required to produce the $n$th unit, $T_{1}$ is the time required to produce the first unit, $n$ is the production count, $b$ is the slope of the learning curve which is often expressed as $b=-\log (\varphi / 100) / \log 2 . \varphi$ is the learning rate expressed as a percentage.

Though Wright's simple mathematical expression is easier to understand and implement, it has some drawbacks that made it necessary for researchers to apply some correction factors to the model. One of the drawbacks is that the result obtained becomes practically meaningless when cumulative production (with learning) approaches infinity (Jaber \& Bonney, 1999). Since for any positive learning rate the time required to produce the $n$th unit according to Wright's model approaches zero as $n$ approaches infinity. This is at variance with real-world situations wherein there exists a minimum value of time $\left(T_{\min }\right)$, and as $n$ approaches infinity $T_{n}$ approaches $T_{\min }$ (Alamri \& Balkhi 2007). 
To incorporate the effect of learning in set-up into lot sizing models, most researchers applied the Wright's power function model to set-up costs with some modifications. Chand (1989) used a loglinear learning function to generate set-up costs in his computational study that investigated the effects of learning in set-ups on set-up frequency. In this case, the cost of the $n$-th set-up, $K(n)$, is given by:

$$
K(n)=K_{\infty}+\left(K_{0}-K_{\infty}\right) n^{-\varepsilon},
$$

where $K_{0}$ is the cost of the maximum (initial) set-up and $K_{\infty}$ is the minimum set-up cost. The learning function is made up of two components, a minimum set-up cost and a conventional learning curve $\left(100\left(2^{-b}\right) \%\right)$ on the reducible set-up cost $\left(K_{0}-K_{\infty}\right)$. Chand $(1989)$ used the following values for $\varepsilon$ : $0.1,0.3,0.5,0.7,0.9$, and 1.3 . These values represent $93.3 \%, 81.2 \%, 70.7 \%, 61.5 \%, 53.5 \%$, and $40.6 \%$ learning curves, respectively.

Cheng (1994) assumed that set-up and unit variable manufacturing costs decrease as a result of learning over time and that some percentage of learning is lost between consecutive orders. He obtained the cost of the $i$-th set-up using $S_{i}=S_{1} i^{b}$, where $b<0$ is the learning index of the set-up operation and $S_{1}$ is the cost of the first set-up.

Rachamadugu and Schriber (1995) computed the set-up costs using a power function similar to a modified version of Wright (1936) power function thus: $S_{i}=S_{1} i^{-b} \quad \forall\left\{i \mid S_{i} \geq S_{\min }\right\}$.

Using similar learning relationship to the above, Jabber and Bonney (2003) computed the cost of $n$-th set-up $\left(K_{n}\right)$ using the equation below:

$K_{n}= \begin{cases}K_{1} n^{-b} & \text { if } n<n_{s}, \\ K_{\min } & \text { if } n \geq n_{s} .\end{cases}$

$K_{\min }$ is the minimum set-up cost that could be achieved when $n=n_{s}$, and $n_{s} \cong\left(K_{\min } / K_{1}\right)^{-1 / b}$.

Jaber and Bonney (2003) described the above model as an adjusted version of the Wright's learning curve with the introduction of a plateau effect. He demonstrated its advantages over the learning curve model adopted by Chand (1989) especially for firms that might plan to shift from traditional economic order quantity to a JIT system through set-up reduction with a target set-up cost of $K_{\min }$. Das et al. (2010) assumed a set-up cost in a cycle is partly constant and partly decreasing in the cycle due to learning effects of the employees and determined the set-up cost in the $j$-th period using $C_{j}=C_{3}+C_{3}^{\prime} e^{-\beta j}$, where $\beta(>0)$ is the learning coefficient associated with the set-up cost.

From the foregoing, it is obvious that most researchers considering the effect of learning in set-up agree to the existence of a minimum value of the set-up cost that cannot be affected by learning. This is a reasonable assumption when we consider the fact that there are some aspects of the set-up cost that may not be subject to the reduction due to learning.

Some researchers have equally modelled the effect of loss of learning (forgetting) in the set-up cost (e,g. Chiu et al., 2003; Jaber et al., 2010) but unlike the learning process a full understanding of the forgetting process is yet to be developed (Jaber \& Bonney, 2003).

In this paper, we study the effect of learning in set-up in a multi-period production inventory system involving seasonal products with a three phase ramp demand pattern and Weibull distribution deterioration. The set-up cost is assumed to reduce due to learning effect and the cost of $n$-th set-up is computed using the learning curve with plateau effect proposed in Jaber and Bonney (2003).

\section{Model formulation}

\subsection{Assumptions and notations}


The major assumptions of the model are as follows:

1. A single item multi-period production-inventory system is considered.

2. The production rate of the item is a known function of demand rate.

3. Demand rate is a general time dependent three-phase ramp-type function.

4. Deterioration rate of the item is represented by a two-parameter Weibull-distribution function.

5. No repair or replacement of deteriorated items during the period.

6. Set-up cost decreases due to the learning in set-ups while set-up time is negligible.

7. Production cost per unit and inventory holding cost per unit are known and constant.

The following notations are used in formulating the models:

$t_{i-1}$ is the time when production for the $i$-th cycle begins

$s_{i}$ is the time when production for the $i$-th cycle stops

$t_{i}$ is the end of the $i$-th cycle

$T_{i}=t_{i}-t_{i-1}$ is the length of a cycle

$q_{i-1}$ is the inventory level at the beginning of the $i$-th cycle

$q_{i}$ is the inventory level at the end of the $i$-th cycle

$K(t)=\alpha f(t)$ is the production rate $(\alpha>1)$

$C_{P}$ is the production cost per unit

$C_{H}$ is the inventory holding cost per unit

$A_{n}= \begin{cases}A_{1} n^{-c} & \text { if } n<n_{s} \\ A_{\text {min }} & \text { if } n \geq n_{s}\end{cases}$

$A_{1}$ is the cost of the first set-up, $A_{n}$ is the cost of $n$th set-up, $A_{\min }$ is the minimum set-up that is obtainable when $n=n_{s}, c$ is the slope of the learning curve.

Demand rate $f(t)$ is a general time dependent ramp-type functions (see Fig 1), and is of the form:

$$
\begin{aligned}
& f(t)=\left\{\begin{array}{l}
g(t), 0 \leq t \leq \mu, \\
g(\mu), \quad \mu \leq t \leq \gamma, \\
h(t), t \geq \gamma .
\end{array}\right. \\
& g(t) \geq 0, h(t) \geq 0,0 \leq \mu \leq \gamma, g(\mu)=h(\gamma) .
\end{aligned}
$$

The function $g(t)$ can be a continuous and non-decreasing function of time, while $h(t)$ is a continuous and non-increasing function of time in the given interval. Parameters ' $\mu$ ' and ' $\gamma$ ' represent the trend of the ramp-type demand function.

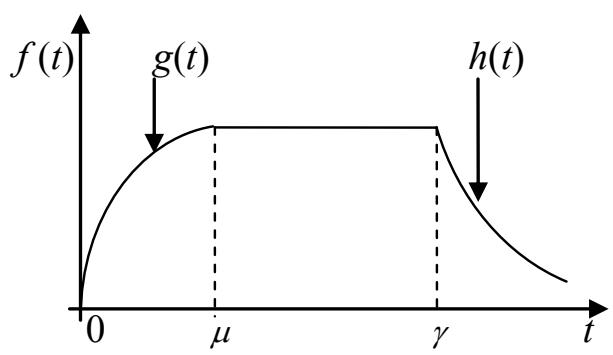

Fig. 1. The three-phase ramp-type demand pattern

The system consists of several production-inventory cycles. Each cycle begins with the production at time $t_{i-1}$ and ends with the consumption due to demand and deterioration at time $t_{i}$. The production stops at time $s_{i}$ within the interval while demand and deterioration of products occur throughout the interval. To allow for a fast-response to customers' demand, the next production cycle begins when the inventory level in the current cycle drops to a predetermined value $\left(q_{i}\right)$. As for this strategy, no shortage or back order occurs as the inventory level gets to zero only at the beginning of the first cycle and at the end of the last cycle. With the three-phase ramp-type demand pattern, a production 
cycle may encounter a different demand pattern during the cycle and the manager is faced with the multiple choices of production options to satisfy these demands. He will have to consider all these options properly and decide on the optimal option. The variation of inventory level with time for a typical cycle is shown in Fig. 2 and the various possible options at the disposal of the manager are considered in the cases below followed by the analysis of the cost of each option.

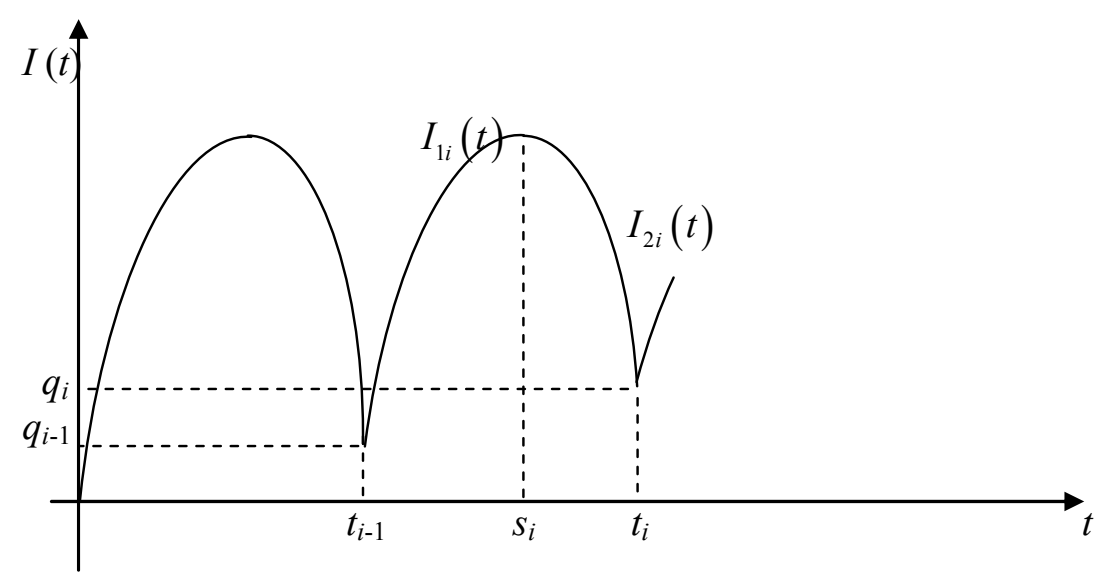

Fig. 2. Variation of inventory level with time for a typical cycle (Case 1)

\subsection{Case 1: A cycle with single demand pattern}

Production begins at $t=t_{i-1}$ and stops at $t=s_{i}$. The consumption within the interval due to demand and deterioration also takes place. In the interval $\left[s_{\mathrm{i}}, t_{i}\right]$, production ceases and consumption continue to reduce the level of accumulated inventory. The rate of change of inventory level with time is as follows:

$$
\begin{array}{ll}
\frac{d I_{1 i}(t)}{d t}=K(t)-f(t)-\theta(t) I_{1 i}(t) & t_{i-1} \leq t \leq s_{i} ; I_{1 i}\left(t_{i-1}\right)=q_{i-1}, \\
\frac{d I_{2 i}(t)}{d t}=-f(t)-\theta(t) I_{2 i}(t), & s_{i} \leq t \leq t_{i} ; I_{2 i}\left(t_{i}\right)=q_{i} .
\end{array}
$$

Here we consider all production and consumption cycles that do not involve a change in demand pattern. The demand pattern may be any of the patterns given in $f(t)$. Inventory level at any time during the production stage of the $i$-th cycle is represented by $I_{1 i}(t)$ while $I_{2 i}(t)$ is the inventory level at any time during the no-production stage of the $i$-th cycle.

The solutions to Eq. (1) above are as follows:

$$
\begin{aligned}
& I_{1 i}(t)=q_{i-1} e^{a\left(t_{i-1}^{b}-t^{b}\right)}+e^{-a t^{b}} \int_{t_{i-1}}^{t} e^{a x^{b}}(K(x)-f(x)) d x, \quad t_{i-1} \leq t \leq s_{i}, \\
& I_{2 i}(t)=q_{i} e^{a\left(t_{i}^{b}-t^{b}\right)}+e^{-a t^{b}} \int_{t}^{t_{i}} e^{a x^{b}} f(x) d x \quad s_{i} \leq t \leq t_{i} .
\end{aligned}
$$

The inventory holding cost, the production cost, and the set-up cost for one cycle under this case are as follows:

$$
\begin{aligned}
& H C_{i}=C_{H}\left(\int_{t_{i-1}}^{s_{i}} I_{1 i}(t) d t+\int_{s_{i}}^{t_{i}} I_{2 i}(t) d t\right), \\
& P R C_{i}=C_{P} \int_{t_{i-1}}^{s_{i}} K(t) d t, \\
& S U C_{i}=A_{n} .
\end{aligned}
$$


The total relevant cost per unit time for one cycle is as follows:

$$
\begin{aligned}
T C T_{1 i}\left(s_{i}, t_{i}\right) & =\frac{1}{\left(t_{i}-t_{i-1}\right)}\left(H C_{i}+P R C_{i}+S U C_{i}\right), \\
& =\frac{1}{\left(t_{i}-t_{i-1}\right)}\left(C_{H}\left(\int_{t_{i-1}}^{s_{i}} I_{1 i}(t) d t+\int_{s_{i}}^{t_{i}} I_{2 i}(t) d t\right)+C_{P} \int_{t_{i-1}}^{s_{i}} K(t) d t+A_{n}\right) .
\end{aligned}
$$

The optimal production schedules and the cost for the first and the subsequent cycles can be obtained using different values of learning rate by minimizing $T C T_{1 i}\left(s_{i}, t_{i}\right)$ subject to the constraints below.
I. $I_{1 i}\left(s_{i}\right)=I_{2 i}\left(s_{i}\right)$,
II. $0<t_{i-1}<s_{i}<t_{i}$.

\subsection{Case 2: Cycle with demand pattern variation once during no-production stage}

The cycle begins with production at time $t_{i-1}\left(0 \leq t_{i-1}<\mu\right)$, and production is stopped at time $s_{i}$ ( $\left.0<s_{i} \leq \mu\right)$. This is followed by the no-production stage that ends at time $t_{i}\left(\mu<t_{i}<\gamma\right)$ when the inventory gets to a pre-determined level. The demand pattern changes during the no-production stage from $g(t)$ to $g(\mu)$. The behavior of the inventory level in this case is described by the following equations:

$$
\begin{array}{ll}
\frac{d I_{1 i}(t)}{d t}=K(t)-g(t)-\theta(t) I_{1 i}(t) & t_{i-1} \leq t \leq s_{i} ; I_{1 i}\left(t_{i-1}\right)=q_{i-1}, \\
\frac{d I_{2 i}(t)}{d t}=-g(t)-\theta(t) I_{2 i}(t), & s_{i} \leq t \leq \mu ; I_{2 i}(\mu)=I_{3 i}(\mu), \\
\frac{d I_{3 i}(t)}{d t}=-g(\mu)-\theta(t) I_{3 i}(t), & \mu \leq t \leq t_{i} ; I_{3 i}\left(t_{i}\right)=q_{i} .
\end{array}
$$

In this case $I_{2 i}(t)$, and $I_{3 i}(t)$ represent the inventory levels during the no-production stage of the cycle while $I_{1 i}(t)$ is the inventory level during the production stage. The solutions to Eq. (5) are as follows:

$$
\begin{aligned}
& I_{1 i}(t)=q_{i-1} e^{a\left(t_{i-1}^{b}-t^{b}\right)}+e^{-a t^{b}} \int_{t_{i-1}}^{t} e^{a x^{b}}(K(x)-g(x)) d x, \quad t_{i-1} \leq t \leq s_{i}, \\
& I_{2 i}(t)=q_{i} e^{a\left(t_{i}^{b}-t^{b}\right)}+e^{-a t^{b}}\left(\int_{t}^{\mu} e^{a x^{b}} g(x) d x+\int_{\mu}^{t_{i}} e^{a x^{b}} g(\mu) d x\right), \quad s_{i} \leq t \leq \mu, \\
& I_{3 i}(t)=q_{i} e^{a\left(t_{i}^{b}-t^{b}\right)}+e^{-a t^{b}} \int_{t}^{t_{i}} e^{a x^{b}} g(\mu) d x \quad \mu \leq t \leq t_{i} .
\end{aligned}
$$

The inventory holding cost, the production cost, and the set-up cost for one cycle are as follows:

$$
\begin{aligned}
& H C_{i}=C_{H}\left(\int_{t_{i-1}}^{s_{i}} I_{1 i}(t) d t+\int_{s_{i}}^{\mu} I_{2 i}(t) d t+\int_{\mu}^{t_{i}} I_{3 i}(t) d t\right), \\
& P R C_{i}=C_{P} \int_{t_{i-1}}^{s_{i}} K(t) d t, \\
& S U C_{i}=A_{n} .
\end{aligned}
$$

The total relevant cost per unit time for one cycle is as follows: 


$$
\begin{aligned}
\operatorname{TCT}_{2 i}\left(s_{i}, t_{i}\right) & =\frac{1}{\left(t_{i}-t_{i-1}\right)}\left(H C_{i}+P R C_{i}+S U C_{i}\right), \\
= & \frac{1}{\left(t_{i}-t_{i-1}\right)}\left(\begin{array}{l}
C_{H}\left(\int_{t_{i-1}}^{s_{i}} I_{1 i}(t) d t+\int_{s_{i}}^{\mu} I_{2 i}(t) d t+\int_{\mu}^{t_{i}} I_{3 i}(t) d t\right) \\
+C_{P} \int_{t_{i-1}}^{s_{i}} K(t) d t+A_{n}
\end{array}\right) .
\end{aligned}
$$

The optimal production schedules and the cost for the cycle can be obtained by minimizing $T C T_{2 i}\left(s_{i}, t_{i}\right)$ subject to the constraints below.

I. $I_{1 i}\left(s_{i}\right)=I_{2 i}\left(s_{i}\right)$,

II. $0<t_{i-1}<s_{i}<\mu<t_{i}<\gamma$.

\subsection{Case 3: A cycle with demand pattern varying once during production}

The inventory behavior in this case is similar to Case 2 except that, in this case production is stopped while the demand is constant (i.e. $0<t_{i-1}<\mu, \mu \leq s_{i}<\gamma, \mu<t_{i}<\gamma$ ). The demand pattern also changes from $g(t)$ to $g(\mu)$ during the production stage. The equation of the system is as follows:

$$
\begin{aligned}
& \frac{d I_{1 i}(t)}{d t}=K(t)-g(t)-\theta(t) I_{1 i}(t) \quad t_{i-1} \leq t \leq \mu ; I_{1 i}\left(t_{i-1}\right)=q_{i-1}, \\
& \frac{d I_{2 i}(t)}{d t}=K(t)-g(\mu)-\theta(t) I_{2 i}(t) \quad \mu \leq t \leq s_{i} ; I_{1 i}(\mu)=I_{2 i}(\mu), \\
& \frac{d I_{3 i}(t)}{d t}=-g(\mu)-\theta(t) I_{3 i}(t), \quad s_{i} \leq t \leq t_{i} ; I_{2 i}\left(t_{i}\right)=q_{i} .
\end{aligned}
$$

$I_{1 i}(t)$ and $I_{2 i}(t)$ represent the inventory levels during the production stage while $I_{3 i}(t)$ represents the inventory level during the no-production stage. The solutions to Eq. (9) are as follows:

$$
\begin{aligned}
& I_{1 i}(t)=q_{i-1} e^{a\left(t_{i-1}^{b}-t^{b}\right)}+e^{-a t^{b}} \int_{t_{i-1}}^{t} e^{a x^{b}}(K(x)-g(x)) d x, \quad t_{i-1} \leq t \leq \mu, \\
& I_{2 i}(t)=q_{i-1} e^{a\left(t_{i-1}^{b}-t^{b}\right)}+e^{-a t^{b}}\left(\int_{\mu}^{t} e^{a x^{b}}(K(x)-g(\mu)) d x+\int_{t_{i-1}}^{\mu} e^{a x^{b}}(K(x)-g(x)) d x\right), \mu \leq t \leq s_{i}, \\
& I_{3 i}(t)=q_{i} e^{a\left(t_{i}^{b}-t^{b}\right)}+e^{-a t^{b}} \int_{t}^{t_{i}} e^{a x^{b}} g(\mu) d x, \quad s_{i} \leq t \leq t_{i} .
\end{aligned}
$$

The inventory holding cost, the production cost, and the set-up cost for one cycle are as follows:

$$
\begin{aligned}
& H C_{i}=C_{H}\left(\int_{t_{i-1}}^{\mu} I_{1 i}(t) d t+\int_{\mu}^{s_{i}} I_{2 i}(t) d t+\int_{s_{i}}^{t_{i}} I_{3 i}(t) d t\right), \\
& P R C_{i}=C_{P} \int_{t_{i-1}}^{s_{i}} K(t) d t, \\
& S U C_{i}=A_{n} .
\end{aligned}
$$

The total relevant cost per unit time for one cycle is as follows:

$$
\operatorname{TCT}_{3 i}\left(s_{i}, t_{i}\right)=\frac{1}{\left(t_{i}-t_{i-1}\right)}\left(\begin{array}{l}
C_{H}\left(\int_{t_{i-1}}^{\mu} I_{1 i}(t) d t+\int_{\mu}^{s_{i}} I_{2 i}(t) d t+\int_{s_{i}}^{t_{i}} I_{3 i}(t) d t\right) \\
+C_{P} \int_{t_{i-1}}^{s_{i}} K(t) d t+A_{n}
\end{array}\right) .
$$

Minimizing $\operatorname{TCT}_{3 i}\left(s_{i}, t_{i}\right)$ subject to the constraints below gives the optimal production schedule and cost for the cycle. 
I. $I_{2 i}\left(s_{i}\right)=I_{3 i}\left(s_{i}\right)$,

II. $0<t_{i-1}<\mu<s_{i}<t_{i}<\gamma$.

\subsection{Case 4: A cycle with demand pattern declining once during no-production stage}

In this case, the cycle begins with the production at time $t_{i-1}\left(\mu \leq t_{i-1}<\gamma\right)$ when the demand is constant. The production stops at time $s_{i}\left(\mu<s_{i}<\gamma\right)$ when the demand is still constant. The demand pattern changes from constant to declining pattern (i.e. from $g(\mu)$ to $h(t)$ ) during the no-production stage. The equation of the system during this stage is as follows:

$$
\begin{aligned}
& \frac{d I_{1 i}(t)}{d t}=K(t)-g(\mu)-\theta(t) I_{1 i}(t) \quad t_{i-1} \leq t \leq s_{i} ; I_{1 i}\left(t_{i-1}\right)=q_{i-1}, \\
& \frac{d I_{2 i}(t)}{d t}=-g(\mu)-\theta(t) I_{2 i}(t), \quad s_{i} \leq t \leq \gamma ; I_{2 i}(\gamma)=I_{3 i}(\gamma), \\
& \frac{d I_{3 i}(t)}{d t}=-h(t)-\theta(t) I_{3 i}(t), \quad \gamma \leq t \leq t_{i} ; I_{3 i}\left(t_{i}\right)=q_{i} .
\end{aligned}
$$

$I_{1 i}(t)$ represents the inventory levels during the production stage while $I_{2 i}(t)$ and $I_{3 i}(t)$ represent the inventory level during the no-production stage. The solutions to Eq. (13) are as follows:

$$
\begin{aligned}
& I_{1 i}(t)=q_{i-1} e^{a\left(t_{i-1}^{b}-t^{b}\right)}+e^{-a t^{b}} \int_{t_{i-1}}^{t} e^{a x^{b}}(K(x)-g(\mu)) d x, \quad t_{i-1} \leq t \leq s_{i}, \\
& I_{2 i}(t)=q_{i} e^{a\left(t_{i}^{b}-t^{b}\right)}+e^{-a t^{b}}\left(\int_{t}^{\gamma} e^{a x^{b}} g(\mu) d x+\int_{\gamma}^{t_{i}} e^{a x^{b}} h(x) d x\right), \quad s_{i} \leq t \leq \gamma, \\
& I_{3 i}(t)=q_{i} e^{a\left(t_{i}^{b}-t^{b}\right)}+e^{-a t^{b}} \int_{t}^{t_{i}} e^{a x^{b}} h(x) d x \quad \quad \gamma \leq t \leq t_{i} .
\end{aligned}
$$

The total relevant cost per unit time for the cycle is as follows:

$$
\operatorname{TCT}_{4 i}\left(s_{i}, t_{i}\right)=\frac{1}{\left(t_{i}-t_{i-1}\right)}\left(\begin{array}{l}
C_{H}\left(\int_{t_{i-1}}^{s_{i}} I_{1 i}(t) d t+\int_{s_{i}}^{\gamma} I_{2 i}(t) d t+\int_{\gamma}^{t_{i}} I_{3 i}(t) d t\right) \\
+C_{P} \int_{t_{i-1}}^{s_{i}} K(t) d t+A_{n}
\end{array}\right) .
$$

Minimizing $\operatorname{TCT}_{4 i}\left(s_{i}, t_{i}\right)$ subject to the constraints below gives the optimal production schedule and cost for the cycle.
I. $I_{1 i}\left(s_{i}\right)=I_{2 i}\left(s_{i}\right)$,
II. $\mu \leq t_{i-1}<s_{i}<\gamma<t_{i}$.

\subsection{Case 5: A cycle with demand pattern varying (declining) once during production}

The inventory behavior in this case is similar to Case 4 with the exception that production is stopped while the demand is decreasing (i.e. $\mu \leq t_{i-1}<\gamma, s_{i}>\gamma, t_{i}>\gamma$ ). The demand pattern also changes from $g(\mu)$ to $h(t)$ during the production. The equation of the system during this stage is: 


$$
\begin{aligned}
& \frac{d I_{1 i}(t)}{d t}=K(t)-g(\mu)-\theta(t) I_{1 i}(t) \quad t_{i-1} \leq t \leq \gamma ; I_{1 i}\left(t_{i-1}\right)=q_{i-1}, \\
& \frac{d I_{2 i}(t)}{d t}=K(t)-h(t)-\theta(t) I_{2 i}(t) \quad \gamma \leq t \leq s_{i} ; I_{1 i}(\gamma)=I_{2 i}(\gamma), \\
& \frac{d I_{3 i}(t)}{d t}=-h(\mu)-\theta(t) I_{3 i}(t), \quad s_{i} \leq t \leq t_{i} ; I_{3 i}\left(t_{i}\right)=q_{i} .
\end{aligned}
$$

$I_{1 i}(t)$ and $I_{2 i}(t)$ represent the inventory levels during the production stage while $I_{3 i}(t)$ represents the inventory level during the no-production stage. The solutions to Eq. (16) are as follows:

$$
\begin{aligned}
& I_{1 i}(t)=q_{i-1} e^{a\left(t_{i-1}^{b}-t^{b}\right)}+e^{-a t^{b}} \int_{t_{i-1}}^{t} e^{a x^{b}}(K(x)-g(\mu)) d x, \quad t_{i-1} \leq t \leq \gamma, \\
& I_{2 i}(t)=q_{i-1} e^{a\left(t_{i-1}^{b}-t^{b}\right)}+e^{-a t^{b}}\left(\int_{\gamma}^{t} e^{a x^{b}}(K(x)-h(x)) d x+\int_{t_{i-1}}^{\gamma} e^{a x^{b}}(K(x)-g(\mu)) d x\right), \gamma \leq t \leq s_{i}, \\
& I_{3 i}(t)=q_{i} e^{a\left(t_{i}^{b}-t^{b}\right)}+e^{-a t^{b}} \int_{t}^{t_{i}} e^{a x^{b}} h(x) d x, \quad s_{i} \leq t \leq t_{i} .
\end{aligned}
$$

The total relevant cost per unit time for the cycle is as follows:

$$
\operatorname{TCT}_{5 i}\left(s_{i}, t_{i}\right)=\frac{1}{\left(t_{i}-t_{i-1}\right)}\left(\begin{array}{l}
C_{H}\left(\int_{t_{i-1}}^{\gamma} I_{1 i}(t) d t+\int_{\gamma}^{s_{i}} I_{2 i}(t) d t+\int_{s_{i}}^{t_{i}} I_{3 i}(t) d t\right) \\
+C_{P} \int_{t_{i-1}}^{s_{i}} K(t) d t+A_{n}
\end{array}\right) .
$$

Minimizing $T C T_{5 i}\left(s_{i}, t_{i}\right)$ subject to the constraints below gives the optimal production schedule and cost for the cycle.

I. $I_{2 i}\left(s_{i}\right)=I_{3 i}\left(s_{i}\right)$,

II. $\mu \leq t_{i-1}<\gamma<s_{i}<t_{i}$.

\subsection{Case 6: A cycle with variation in demand pattern twice during no-production stage}

The cycle begins with the production at time $t_{i-1}\left(0 \leq t_{i-1}<\mu\right)$, and the production is stopped at time $s_{i}\left(0<s_{i}<\mu\right)$ while the demand rate is $g(t)$. The no-production stage follows and ends at time $t_{i}$ $\left(t_{i}>\gamma\right)$. The demand pattern changes twice during no-production stage, the first from $g(t)$ to $g(\mu)$ and the later from $g(\mu)$ to $h(t)$.The equation of the system is as follows:

$$
\begin{aligned}
& \frac{d I_{1 i}(t)}{d t}=K(t)-g(t)-\theta(t) I_{1 i}(t) \quad t_{i-1} \leq t \leq s_{i} ; I_{1 i}\left(t_{i-1}\right)=q_{i-1}, \\
& \frac{d I_{2 i}(t)}{d t}=-g(t)-\theta(t) I_{2 i}(t), \quad s_{i} \leq t \leq \mu ; I_{2 i}(\mu)=I_{3 i}(\mu), \\
& \frac{d I_{3 i}(t)}{d t}=-g(\mu)-\theta(t) I_{3 i}(t), \quad \mu \leq t \leq \gamma ; I_{3 i}(\gamma)=I_{4 i}(\gamma), \\
& \frac{d I_{4 i}(t)}{d t}=-h(t)-\theta(t) I_{4 i}(t), \quad \gamma \leq t \leq t_{i} ; I_{4 i}\left(t_{i}\right)=q_{i} .
\end{aligned}
$$

While $I_{1 i}(t)$ represents the inventory level during the production, $I_{2 i}(t)$, and $I_{3 i}(t), I_{4 i}(t)$, represent the inventory levels during the no-production stage of the cycle. Solutions to Eq. (19) are as follows: 


$$
\begin{aligned}
& I_{1 i}(t)=q_{i-1} e^{a\left(t_{i-1}^{b}-t^{b}\right)}+e^{-a t^{b}} \int_{t_{i-1}}^{t} e^{a x^{b}}(K(x)-g(x)) d x, \quad t_{i-1} \leq t \leq s_{i}, \\
& I_{2 i}(t)=q_{i} e^{a\left(t_{i}^{b}-t^{b}\right)}+e^{-a t^{b}}\left(\int_{t}^{\mu} e^{a x^{b}} g(x) d x+\int_{\mu}^{\gamma} e^{a x^{b}} g(\mu) d x+\int_{\gamma}^{t_{i}} e^{a x^{b}} h(x) d x\right), \quad s_{i} \leq t \leq \mu, \\
& I_{3 i}(t)=q_{i} e^{a\left(t_{i}^{b}-t^{b}\right)}+e^{-a t^{b}}\left(\int_{t}^{\gamma} e^{a x^{b}} g(\mu) d x+\int_{\gamma}^{t_{i}} e^{a x^{b}} h(x) d x\right), \quad \mu \leq t \leq \gamma, \\
& I_{4 i}(t)=q_{i} e^{a\left(t_{i}^{b}-t^{b}\right)}+e^{-a t^{b}} \int_{t}^{t_{i}} e^{a x^{b}} h(x) d x \quad \quad \gamma \leq t \leq t_{i} .
\end{aligned}
$$

Total relevant cost per unit time for the cycle is as follows:

$$
\operatorname{TCT}_{6 i}\left(s_{i}, t_{i}\right)=\frac{1}{\left(t_{i}-t_{i-1}\right)}\left(\begin{array}{l}
C_{H}\left(\int_{t_{i-1}}^{s_{i}} I_{1 i}(t) d t+\int_{s_{i}}^{\mu} I_{2 i}(t) d t+\int_{\mu}^{\gamma} I_{3 i}(t) d t+\int_{\gamma}^{t_{i}} I_{4 i}(t) d t\right) \\
+C_{P} \int_{t_{i-1}}^{s_{i}} K(t) d t+A_{n}
\end{array}\right) .
$$

Minimizing $\operatorname{TCT}_{6 i}\left(s_{i}, t_{i}\right)$ subject to the constraints below gives the optimal production schedule and cost for the cycle.

I. $I_{1 i}\left(s_{i}\right)=I_{2 i}\left(s_{i}\right)$,

II. $0 \leq t_{i-1}<s_{i}<\mu<\gamma<t_{i}$.

\subsection{Case 7: A cycle with variation in demand pattern during and after the production stage}

In this case, the production begins at $t_{i-1}\left(0 \leq t_{i-1}<\mu\right)$ and stops at $s_{i}\left(\mu \leq s_{i}<\gamma\right)$. The no-production stage follows till the time $t_{i}\left(t_{i}>\gamma\right)$. The demand pattern changes during the production from $g(t)$ to $g(\mu)$ and also from $g(\mu)$ to $h(t)$ during no-production stage. The equation of the system is as follows:

$$
\begin{aligned}
& \frac{d I_{1 i}(t)}{d t}=K(t)-g(t)-\theta(t) I_{1 i}(t) \quad t_{i-1} \leq t \leq \mu ; I_{1 i}\left(t_{i-1}\right)=q_{i-1}, \\
& \frac{d I_{2 i}(t)}{d t}=K(t)-g(\mu)-\theta(t) I_{2 i}(t), \quad \mu \leq t \leq s_{i} ; I_{1 i}(\mu)=I_{2 i}(\mu), \\
& \frac{d I_{3 i}(t)}{d t}=-g(\mu)-\theta(t) I_{3 i}(t), \quad s_{i} \leq t \leq \gamma ; I_{3 i}(\gamma)=I_{4 i}(\gamma), \\
& \frac{d I_{4 i}(t)}{d t}=-h(t)-\theta(t) I_{4 i}(t), \quad \gamma \leq t \leq t_{i} ; I_{4 i}\left(t_{i}\right)=q_{i} .
\end{aligned}
$$

While $I_{1 i}(t)$ and $I_{2 i}(t)$ represent the inventory levels during the production stage, $I_{3 i}(t)$ and $I_{4 i}(t)$, represent the inventory levels during the no-production stage. The solutions to Eq. (22) are as follows:

$$
\begin{aligned}
& I_{1 i}(t)=q_{i-1} e^{a\left(t_{i-1}^{b}-t^{b}\right)}+e^{-a t^{b}} \int_{t_{i-1}}^{t} e^{a x^{b}}(K(x)-g(x)) d x, \quad t_{i-1} \leq t \leq \mu, \\
& I_{2 i}(t)=q_{i-1} e^{a\left(t_{i-1}^{b}-t^{b}\right)}+e^{-a t^{b}}\left(\int_{\mu}^{t} e^{a x^{b}}(K(x)-g(\mu)) d x+\int_{t_{i-1}}^{\mu} e^{a x^{b}}(K(x)-g(x)) d x\right), \mu \leq t \leq s_{i}, \\
& I_{3 i}(t)=q_{i} e^{a\left(t_{i}^{b}-t^{b}\right)}+e^{-a t^{b}}\left(\int_{t}^{\gamma} e^{a x^{b}} g(\mu) d x+\int_{\gamma}^{t_{i}} e^{a x^{b}} h(x) d x\right), \quad s_{i} \leq t \leq \gamma \\
& I_{4 i}(t)=q_{i} e^{a\left(t_{i}^{b}-t^{b}\right)}+e^{-a t^{b}} \int_{t}^{t_{i}} e^{a x^{b}} h(x) d x, \quad \gamma \leq t \leq t_{i} .
\end{aligned}
$$


The total relevant cost per unit time for the cycle is as follows:

$$
\operatorname{TCT}_{7 i}\left(s_{i}, t_{i}\right)=\frac{1}{\left(t_{i}-t_{i-1}\right)}\left(\begin{array}{l}
C_{H}\left(\int_{t_{i-1}}^{\mu} I_{1 i}(t) d t+\int_{\mu}^{s_{i}} I_{2 i}(t) d t+\int_{s_{i}}^{\gamma} I_{3 i}(t) d t+\int_{\gamma}^{t_{i}} I_{4 i}(t) d t\right) \\
+C_{P} \int_{t_{i-1}}^{s_{i}} K(t) d t+A_{n}
\end{array}\right) .
$$

Minimizing $\operatorname{TCT}_{7 i}\left(s_{i}, t_{i}\right)$ subject to the constraints below gives the optimal production schedule and cost for the cycle.
I. $I_{2 i}\left(s_{i}\right)=I_{3 i}\left(s_{i}\right)$,
II. $0 \leq t_{i-1}<\mu<s_{i}<\gamma<t_{i}$.

\subsection{Case 8: A cycle with variation in demand pattern twice during production}

The production stops at time $s_{i}$ when demand is declining and consumption continues till $t_{i}\left(0 \leq t_{i-1}<\mu, s_{i} \geq \gamma, t_{i}>\gamma\right)$. The demand pattern changes twice during production. The equation of the system is as follows:

$$
\begin{aligned}
& \frac{d I_{1 i}(t)}{d t}=K(t)-g(t)-\theta(t) I_{1 i}(t) \quad t_{i-1} \leq t \leq \mu ; I_{1 i}\left(t_{i-1}\right)=q_{i-1}, \\
& \frac{d I_{2 i}(t)}{d t}=K(t)-g(\mu)-\theta(t) I_{2 i}(t), \quad \mu \leq t \leq \gamma ; I_{1 i}(\mu)=I_{2 i}(\mu), \\
& \frac{d I_{3 i}(t)}{d t}=K(t)-h(t)-\theta(t) I_{3 i}(t), \quad \gamma \leq t \leq s_{i} ; I_{2 i}(\gamma)=I_{3 i}(\gamma) \\
& \frac{d I_{4 i}(t)}{d t}=-h(t)-\theta(t) I_{4 i}(t), \quad s_{i} \leq t \leq t ; I_{4 i}\left(t_{i}\right)=q_{i} .
\end{aligned}
$$

The solutions to Eq. (25) are as follows:

$$
\begin{aligned}
& I_{1 i}(t)=q_{i-1} e^{a\left(t_{i-1}^{b}-t^{b}\right)}+e^{-a t^{b}} \int_{t_{i-1}}^{t} e^{a x^{b}}(K(x)-g(x)) d x, \quad t_{i-1} \leq t \leq \mu, \\
& I_{2 i}(t)=q_{i-1} e^{a\left(t_{i-1}^{b}-t^{b}\right)}+e^{-a t^{b}}\left(\int_{\mu}^{t} e^{a x^{b}}(K(x)-g(\mu)) d x+\int_{t_{i-1}}^{\mu} e^{a x^{b}}(K(x)-g(x)) d x\right), \mu \leq t \leq \gamma, \\
& I_{3 i}(t)=q_{i-1} e^{a\left(t_{i-1}^{b}-t^{b}\right)}+e^{-a t^{b}}\left(\begin{array}{l}
\left.\int_{\gamma}^{t} e^{a x^{b}}(K(x)-h(x)) d x+\int_{\mu}^{\gamma} e^{a x^{b}}(K(x)-g(\mu)) d x\right), \gamma \leq t \leq s_{i}, \\
+\int_{t_{i-1}}^{\mu} e^{a x^{b}}(K(x)-g(x)) d x
\end{array}\right), \\
& I_{4 i}(t)=q_{i} e^{a\left(t_{i}^{b}-t^{b}\right)}+e^{-a t^{b}} \int_{t}^{t_{i}} e^{a x^{b}} h(x) d x, \quad s_{i} \leq t \leq t_{i} .
\end{aligned}
$$

The total relevant cost per unit time for the cycle is as follows:

$$
\operatorname{TCT}_{8 i}\left(s_{i}, t_{i}\right)=\frac{1}{\left(t_{i}-t_{i-1}\right)}\left(\begin{array}{l}
C_{H}\left(\int_{t_{i-1}}^{\mu} I_{1 i}(t) d t+\int_{\mu}^{\gamma} I_{2 i}(t) d t+\int_{\gamma}^{s_{i}} I_{3 i}(t) d t+\int_{s_{i}}^{t_{i}} I_{4 i}(t) d t\right) \\
+C_{P} \int_{t_{i-1}}^{s_{i}} K(t) d t+A_{n}
\end{array}\right) .
$$

Minimizing $\operatorname{TCT}_{8 i}\left(s_{i}, t_{i}\right)$ subject to the constraints below gives the optimal production schedule and cost for the cycle.
I. $I_{3 i}\left(s_{i}\right)=I_{4 i}\left(s_{i}\right)$,
II. $0 \leq t_{i-1}<\mu<\gamma<s_{i}<t_{i}$.

\section{Numerical examples and discussion of results}

Consider the production-inventory system for a seasonal product with a three-phase ramp-type 
demand pattern as shown below.

$$
f(t)= \begin{cases}100+5 t, & 0 \leq t \leq \mu, \\ 120, & \mu \leq t \leq \gamma, \\ 120 e^{-0.2(t-8)} & \gamma \leq t \leq T .\end{cases}
$$

The system undergoes a learning-based continuous improvement process which results in reduction in set-up cost. The initial set-up cost prior to any learning is $\$ 200$ per production cycle while the minimum set-up cost that is not subject to further reduction is $\$ 50$ per cycle. The production rate is 1.5 times the demand rate at any point in time; the unit production cost and inventory holding cost per unit of the item are $\$ 10$ and $\$ 1.5$, respectively. The deterioration of the item follows a Weibull distribution ( $\left.\theta(t)=a b t^{b-1}\right)$ with parameters $a=0.005, b=2$. The inventory level at the beginning and end of the season is zero while at other times during the season a minimum inventory level of 50 units is maintained.

The above system is used to illustrate the model by obtaining optimal schedules and costs under different learning rates. This will enable us to study the effects of learning in set-up on the production and inventory schedules and costs. The values used for the learning index $c$ corresponds to learning rates between $40 \%-100 \%$ which is in line with previous studies (e.g. Chand 1989). The system is also used to compare three different production policies that can be adopted when dealing with seasonal products with varying demand patterns. The policies examined are as follows:

- Variable demand pattern (VDP) policy

- Single demand pattern (SDP) policy

- Single production cycle (SPC) policy

The VDP and SDP policies, being multi-period policies, can ensure a fast-response to costumers' demand. The solution procedure for obtaining the optimal schedules and costs under each of these policies along with the numerical examples using the above input data are presented below.

\subsection{Variable demand pattern (VDP) policy}

This policy allows several production cycles during the season without any restrictions by accommodating variation in demand pattern within the cycles whenever they occur.

All production cycles are solved using the procedure for Case 1 except at the points when changes in demand pattern occur. The cycles incorporating the change points are identified and the optimal values for those cycles are recalculated using the appropriate equations. The algorithm for this policy is as follows:

\section{Step 1:}

Determine all the optimal values $\left(s_{i}^{*}, t_{i}^{*}, T C T_{i}^{*}\right)$ for the first and subsequent production cycles using Case 1 by solving a constrained nonlinear optimization problem (CNLOP) problem $P_{1}$ below with an appropriate demand function.

$$
\begin{aligned}
P_{1}= & \min \operatorname{TCT}_{1 i}\left(s_{i}, t_{i}\right) \\
& \text { subject to }\left\{I_{1 i}\left(s_{i}\right)=I_{2 i}\left(s_{i}\right) ; t_{i-1}-s_{i} \leq 0 ; s_{i}-t_{i} \leq 0\right\} .
\end{aligned}
$$

\section{Step 2:}

Check for demand change points by comparing the values of $t_{i}$ and $t_{i-1}$.

\section{Step 3:}

If $0<t_{i-1}<\mu$ and $\mu \leq t_{i} \leq \gamma$ for a given $i$-th cycle, then a change in demand pattern occurred during that cycle. Recalculate the set of values $\left(s_{i}^{*}, t_{i}^{*}, T C T_{i}^{*}\right)$ for that cycle by solving problems $P_{2}$ and $P_{3}$ below. Determine the optimal cost per unit time for that cycle by using $T C T_{i}^{*}=\min \left[T C T_{2 i}^{*}, T C T_{3 i}^{*}\right]$, where $T C T_{2 i}^{*}$, and $T C T_{3 i}^{*}$ are the optimal values obtained from the solution to problems $P_{2}$ and $P_{3}$ 
respectively.

$$
\begin{aligned}
P_{2}= & \min T C T_{2 i}\left(s_{i}, t_{i}\right) \\
& \text { subject to }\left\{I_{1 i}\left(s_{i}\right)=I_{2 i}\left(s_{i}\right) ; 0 \leq t_{i-1}<\mu ; 0 \leq s_{i}<\mu ; t_{i-1}-s_{i} \leq 0 ; s_{i}-t_{i} \leq 0 ; t_{i} \leq \gamma\right\} . \\
P_{3}= & \min T C T_{3 i}\left(s_{i}, t_{i}\right) \\
& \text { subject to }\left\{I_{2 i}\left(s_{i}\right)=I_{3 i}\left(s_{i}\right) ; 0 \leq t_{i-1}<\mu ; \mu \leq s_{i}<\gamma ; t_{i-1}-s_{i} \leq 0 ; s_{i}-t_{i} \leq 0 ; t_{i} \leq \gamma\right\} .
\end{aligned}
$$

\section{Step 4:}

If $\mu \leq t_{i-1}<\gamma$ and $t_{i} \geq \gamma$ for a given $i$-th cycle, then a change in demand pattern occurred during that cycle. Recalculate the set of optimal values $\left(s_{i}^{*}, t_{i}^{*}, T C T_{i}^{*}\right)$ for that cycle by solving problems $P_{4}$ and $P_{5}$ below. Determine the optimal cost per unit time for that cycle by using $T C T_{i}^{*}=\min \left[T C T_{4 i}^{*}, T C T_{5 i}^{*}\right]$, where $T C T_{4 i}^{*}$, and $T C T_{5 i}^{*}$ are the optimal values obtained from the solution to problems $P_{4}$ and $P_{5}$, respectively.

$$
\begin{aligned}
P_{4}= & \min T C T_{4 i}\left(s_{i}, t_{i}\right) \\
& \text { subject to }\left\{I_{1 i}\left(s_{i}\right)=I_{2 i}\left(s_{i}\right) ; \mu \leq t_{i-1}<\gamma ; \mu \leq s_{i} \leq \gamma ; t_{i-1}-s_{i} \leq 0 ; s_{i}-t_{i} \leq 0 ; t_{i} \geq \gamma\right\} . \\
P_{5}= & \min T C T_{5 i}\left(s_{i}, t_{i}\right) \\
& \text { subject to }\left\{I_{2 i}\left(s_{i}\right)=I_{3 i}\left(s_{i}\right) ; \mu \leq t_{i-1}<\gamma ; s_{i} \geq \gamma ; t_{i-1}-s_{i} \leq 0 ; s_{i}-t_{i} \leq 0 ; t_{i} \geq \gamma\right\} .
\end{aligned}
$$

Using the algorithm stated above and the data given earlier in this section the optimal production and inventory schedules and costs for the seasonal item were obtained for various values of learning index $c$. The results are shown in Table 1 below. From the table, the highest value of total relevant cost for the system during the entire season is obtained when the learning index $c$ is zero. This implies that the total relevant cost of the system is at the highest level when there is no improvement and no reduction in set-up cost due to learning. Table 1 also shows that the lowest value of total cost for the season occurs at the highest value of the learning index which corresponds to the highest rate of reduction in set-up cost due to learning. The effect of learning is also reflected in the form of the reduction in cycle length $\left(T_{i}\right)$ as the number of cycles $(n)$ increases for a given demand pattern. This resulted in the increase in the number of lots as the learning index increases, for example when $c$ is 0.5 ; the total number of lots produced is 4 , but for $c=0.75$ and 1.25 , the total number of lots increases to 5 and 6 , respectively. This corroborates the fact that reduction in set-up cost often leads to higher production frequency and shorter production runs, which forms an aspect of the just-in-time (JIT) philosophy (Darwish 2008).

\subsection{Single demand pattern (SDP) policy}

This policy allows several production cycles during the season but ensures that all cycles have single demand pattern by deliberately avoiding change of demand pattern within cycles. The following algorithm is designed to deliberately avoid change of demand pattern within the cycles:

\section{Step 1:}

Determine all the optimal values $\left(s_{i}^{*}, t_{i}^{*}, T C T_{i}^{*}\right)$ for the first and subsequent production cycles using

Case 1 by solving the CNLOP below with appropriate demand function,

\section{Step 2:}

Check for demand change points by comparing the values of $t_{i}$ and $t_{i-1}$,

\section{Step 3:}

If $0<t_{i-1}<\mu$ and $\mu \leq t_{i} \leq \gamma$ for a given $i$-th cycle, then a change in demand pattern occurred during 
that cycle. Set $t_{i}^{*}=\mu$ for that cycle and recalculate the optimal values $\left(s_{i}^{*}, t_{i}^{*}, T C T_{i}^{*}\right)$ for the cycle by solving problem $P_{1}$ with appropriate demand function,

\section{Step 4:}

If $\mu \leq t_{i-1}<\gamma$ and $t_{i} \geq \gamma$ for a given $i$-th cycle, then a change in demand pattern occurred during that cycle. Set $t_{i}^{*}=\gamma$ for that cycle and recalculate the optimal values $\left(s_{i}^{*}, t_{i}^{*}, T C T_{i}^{*}\right)$ for the cycle by solving problem $P_{1}$ with appropriate demand function,

Table 1

Optimal results using the VDP Policy with various values of learning index

\begin{tabular}{|c|c|c|c|c|c|c|c|}
\hline & $n$ & $t_{i-1}^{*}$ & $s_{i}^{*}$ & $t_{i}^{*}$ & $T C T_{i}^{*}$ & $T_{i}^{*}$ & $T C T_{i}^{*} * T_{i}^{*}$ \\
\hline \multirow{4}{*}{$c=0$} & 1 & 0 & 2.6231 & 3.3596 & 1417.43 & 3.3596 & 4762.00 \\
\hline & 2 & 3.3596 & 4.8524 & 5.5227 & 1464.70 & 2.1631 & 3168.29 \\
\hline & 3 & 5.5227 & 7.0736 & 7.7407 & 1484.30 & 2.2180 & 3292.18 \\
\hline & 4 & 7.7407 & 10.3129 & 13 & 866.69 & 5.2593 & 4558.18 \\
\hline \multicolumn{7}{|c|}{ Total relevant cost for the season } & 15780.65 \\
\hline \multirow{4}{*}{$c=0.25$} & 1 & 0 & 2.6231 & 3.3596 & 1417.43 & 3.3596 & 4762.00 \\
\hline & 2 & 3.3596 & 4.7213 & 5.3361 & 1449.30 & 1.9765 & 2864.54 \\
\hline & 3 & 5.3361 & 6.6781 & 7.2643 & 1460.00 & 1.9282 & 2815.17 \\
\hline & 4 & 7.2643 & 10.1307 & 13.0000 & 918.17 & 5.7357 & 5266.35 \\
\hline \multicolumn{7}{|c|}{ Total relevant cost for the season } & 15708.06 \\
\hline \multirow{4}{*}{$c=0.50$} & 1 & 0 & 2.6231 & 3.3596 & 1417.43 & 3.3596 & 4762.00 \\
\hline & 2 & 3.3596 & 4.6008 & 5.1638 & 1435.20 & 1.8042 & 2589.39 \\
\hline & 3 & 5.1638 & 6.3278 & 6.8428 & 1438.60 & 1.6790 & 2415.41 \\
\hline & 4 & 6.8428 & 9.9749 & 13.0000 & 960.31 & 6.1572 & 5912.82 \\
\hline \multicolumn{7}{|c|}{ Total relevant cost for the season } & 15679.62 \\
\hline \multirow{5}{*}{$c=0.75$} & 1 & 0 & 2.6231 & 3.3596 & 1417.43 & 3.3596 & 4762.00 \\
\hline & 2 & 3.3596 & 4.4898 & 5.0046 & 1422.10 & 1.6450 & 2339.35 \\
\hline & 3 & 5.0046 & 6.0159 & 6.4683 & 1420.00 & 1.4637 & 2078.45 \\
\hline & 4 & 6.4683 & 7.3822 & 7.7814 & 1416.90 & 1.3131 & 1860.53 \\
\hline & 5 & 7.7814 & 10.3287 & 13.0000 & 834.13 & 5.2186 & 4352.99 \\
\hline \multicolumn{7}{|c|}{ Total relevant cost for the season } & 15393.33 \\
\hline \multirow{5}{*}{$c=0.90$} & 1 & 0 & 2.6231 & 3.3596 & 1417.43 & 3.3596 & 4762.00 \\
\hline & 2 & 3.3596 & 4.4272 & 4.9148 & 1414.80 & 1.5552 & 2200.30 \\
\hline & 3 & 4.9148 & 5.8449 & 6.2633 & 1409.90 & 1.3485 & 1901.25 \\
\hline & 4 & 6.2633 & 7.0835 & 7.4452 & 1404.90 & 1.1819 & 1660.45 \\
\hline & 5 & 7.4452 & 10.1991 & 13.0000 & 878.42 & 5.5548 & 4879.45 \\
\hline \multicolumn{7}{|c|}{ Total relevant cost for the season } & 15403.45 \\
\hline \multirow{7}{*}{$c=1.25$} & 1 & 0 & 2.6231 & 3.3596 & 1417.43 & 3.3596 & 4762.00 \\
\hline & 2 & 3.3596 & 4.2927 & 4.7205 & 1399.00 & 1.3609 & 1903.90 \\
\hline & 3 & 4.7205 & 5.4866 & 5.8352 & 1389.40 & 1.1147 & 1548.76 \\
\hline & 4 & 5.8352 & 6.4749 & 6.7620 & 1381.30 & 0.9268 & 1280.19 \\
\hline & 5 & 6.7620 & 7.3197 & 7.5668 & 1377.30 & 0.8048 & 1108.45 \\
\hline & 6 & 7.5668 & 10.2456 & 13.0000 & 857.34 & 5.4332 & 4658.10 \\
\hline & \multicolumn{6}{|c|}{ Total relevant cost for the season } & 15261.40 \\
\hline
\end{tabular}

Table 2 below shows the result obtained by applying this algorithm to the production-inventory system described earlier for various values of learning index. The result shows a reduction in the total relevant cost of the system with the increase in the value of learning index in addition to the increase in production frequency as noted earlier. 
Table 2

Optimal results using the SDP Policy with various values of learning index

\begin{tabular}{|c|c|c|c|c|c|c|c|}
\hline & $n$ & $t_{i-1}^{*}$ & $s_{i}^{*}$ & $t_{i}^{*}$ & $T C T_{i}^{*}$ & $T_{i}^{*}$ & $T C T_{i}^{*} * T_{i}^{*}$ \\
\hline \multirow{5}{*}{$c=0$} & 1 & 0 & 2.6231 & 3.3596 & 1417.43 & 3.3596 & 4762.00 \\
\hline & 2 & 3.3596 & 3.7966 & 4.0000 & 1612.60 & 0.6404 & 1032.71 \\
\hline & 3 & 4.0000 & 5.5319 & 6.2132 & 1474.50 & 2.2132 & 3263.36 \\
\hline & 4 & 6.2132 & 7.4619 & 8.0000 & 1492.70 & 1.7868 & 2667.16 \\
\hline & 5 & 8.0000 & 10.4147 & 13.0000 & 829.08 & 5.0000 & 4145.38 \\
\hline \multicolumn{7}{|c|}{ Total relevant cost for the season } & 15870.60 \\
\hline \multirow{5}{*}{$c=0.25$} & 1 & 0 & 2.6231 & 3.3596 & 1417.43 & 3.3596 & 4762.00 \\
\hline & 2 & 3.3596 & 3.7966 & 4.0000 & 1562.77 & 0.6404 & 1000.80 \\
\hline & 3 & 4.0000 & 5.3326 & 5.9310 & 1451.27 & 1.931 & 2802.40 \\
\hline & 4 & 5.9310 & 7.3792 & 8.0000 & 1458.92 & 2.069 & 3018.51 \\
\hline & 5 & 8.0000 & 10.4147 & 13.0000 & 815.82 & 5.0000 & 4079.12 \\
\hline \multicolumn{7}{|c|}{ Total relevant cost for the season } & 15662.82 \\
\hline \multirow{8}{*}{$c=0.50$} & 1 & 0 & 2.6231 & 3.3596 & 1417.43 & 3.3596 & 4762.00 \\
\hline & 2 & 3.3596 & 3.7966 & 4.0000 & 1521.10 & 0.6404 & 974.11 \\
\hline & 3 & 4.0000 & 5.1601 & 5.6853 & 1431.10 & 1.6853 & 2411.83 \\
\hline & 4 & 5.6853 & 6.7703 & 7.2473 & 1432.30 & 1.562 & 2237.25 \\
\hline & 5 & 7.2473 & 7.7702 & 8.0000 & 1464.00 & 0.7527 & 1101.95 \\
\hline & 6 & 8.0000 & 10.4147 & 13.0000 & 814.63 & 5.0000 & 4073.16 \\
\hline & \multicolumn{5}{|c|}{ Total relevant cost for the season } & & 15560.31 \\
\hline & $\mathrm{N}$ & $t_{i-1}^{*}$ & $s_{i}^{*}$ & $t_{i}^{*}$ & $T C T_{i}^{*}$ & $T_{i}^{*}$ & $T C T_{i}^{*} * T_{i}^{*}$ \\
\hline \multirow{6}{*}{$c=0.75$} & 1 & 0 & 2.6231 & 3.3596 & 1417.43 & 3.3596 & 4762.00 \\
\hline & 2 & 3.3596 & 3.7966 & 4.0000 & 1485.91 & 0.6404 & 951.58 \\
\hline & 3 & 4.0000 & 5.0105 & 5.4711 & 1413.50 & 1.4711 & 2079.40 \\
\hline & 4 & 5.4711 & 6.3790 & 6.7836 & 1410.60 & 1.3125 & 1851.41 \\
\hline & 5 & 6.7836 & 7.6309 & 8.0000 & 1410.30 & 1.2164 & 1715.49 \\
\hline & 6 & 8.0000 & 10.4147 & 13.0000 & 799.51 & 5.0000 & 3997.55 \\
\hline \multicolumn{7}{|c|}{ Total relevant cost for the season } & 15357.43 \\
\hline \multirow{6}{*}{$c=0.90$} & 1 & 0 & 2.6231 & 3.3596 & 1417.43 & 3.3596 & 4762.00 \\
\hline & 2 & 3.3596 & 3.7966 & 4.0000 & 1467.57 & 0.6404 & 939.83 \\
\hline & 3 & 4.0000 & 4.9303 & 5.3559 & 1404.10 & 1.3559 & 1903.82 \\
\hline & 4 & 5.3559 & 6.1726 & 6.5390 & 1399.30 & 1.1831 & 1655.51 \\
\hline & 5 & 6.5390 & 7.5582 & 8.0000 & 1401.70 & 1.461 & 2047.88 \\
\hline & 6 & 8.0000 & 10.4147 & 13.0000 & 797.05 & 5.0000 & 3985.25 \\
\hline \multicolumn{7}{|c|}{ Total relevant cost for the season } & 15294.29 \\
\hline \multirow{7}{*}{$c=1.25$} & 1 & 0 & 2.6231 & 3.3596 & 1417.43 & 3.3596 & 4762.00 \\
\hline & 2 & 3.3596 & 3.7966 & 4.0000 & 1431.60 & 0.6404 & 916.80 \\
\hline & 3 & 4.0000 & 4.7675 & 5.1211 & 1384.90 & 1.1211 & 1552.61 \\
\hline & 4 & 5.1211 & 5.7602 & 6.0507 & 1376.90 & 0.9296 & 1279.97 \\
\hline & 5 & 6.0507 & 6.6066 & 6.8562 & 1372.70 & 0.8055 & 1105.71 \\
\hline & 6 & 6.8562 & 7.6526 & 8.0000 & 1377.20 & 1.1438 & 1575.24 \\
\hline & 7 & 8.0000 & 10.4147 & 13.0000 & 792.59 & 5.0000 & 3962.95 \\
\hline \multicolumn{7}{|c|}{ Total relevant cost for the season } & 15155.27 \\
\hline
\end{tabular}

For any given value of learning index, the total number of production lots and total relevant cost of the system generated under this policy is higher than that obtained under the VDP policy. This shows VDP policy outperforms the SDP policy from the costs perspectives. This result further corroborate 
the assertion that it is better to always consider changes in the demand pattern that may occur within production/replenishment cycles because neglecting such changes usually leads to overall increase in production/inventory cost (Abdul \& Murata 2011).

\subsection{Single production cycle (SPC) policy}

Under this policy, there is only one production cycle which begins at the at time $t=0$ and stops at time $t=s_{i}$ However the production stopping time may be while demand is increasing (i.e. Case 6), constant (i.e. Case 7), or decreasing (i.e. Case 8). However the production stopping time may be constant while demand is increasing (i.e. Case 6), (i.e. Case 7), or decreasing (i.e. Case 8). The optimal values under this policy can be obtained by using the following algorithm:

\section{Step 1:}

Formulate a constrained nonlinear optimization problem (CNLOP) for Cases 6, 7, and 8 thus:

Case 6:

$P_{6}=\min T C T_{6 i}\left(s_{i}, t_{i}\right)$

subject to $\left\{I_{1 i}\left(s_{i}\right)=I_{2 i}\left(s_{i}\right) ; 0 \leq t_{i-1}<\mu ; 0 \leq s_{i}<\mu ; t_{i-1}-s_{i} \leq 0 ; s_{i}-t_{i} \leq 0 ; t_{i} \geq \gamma\right\}$.

Case 7:

$P_{7}=\min T C T_{7 i}\left(s_{i}, t_{i}\right)$

subject to $\left\{I_{2 i}\left(s_{i}\right)=I_{3 i}\left(s_{i}\right) ; 0 \leq t_{i-1}<\mu ; \mu \leq s_{i}<\gamma ; t_{i-1}-s_{i} \leq 0 ; s_{i}-t_{i} \leq 0 ; t_{i} \geq \gamma\right\}$.

Case 8:

$$
P_{8}=\min T C T_{8 i}\left(s_{i}, t_{i}\right)
$$

subject to $\left\{I_{3 i}\left(s_{i}\right)=I_{4 i}\left(s_{i}\right) ; 0 \leq t_{i-1}<\mu ; s_{i} \geq \gamma ; t_{i-1}-s_{i} \leq 0 ; s_{i}-t_{i} \leq 0 ; t_{i} \geq \gamma\right\}$.

\section{Step 2:}

Obtain the set of values $\left(s_{i}^{*}, t_{i}^{*}, T C T_{i}^{*}\right)$ for the cycle by solving problems $P_{6}, P_{7}$, and $P_{8}$,

\section{Step 3:}

Determine the optimal values for that cycle by using $T C T_{i}^{*}=\min \left[T C T_{6 i}^{*}, T C T_{7 i}^{*}, T C T_{8 i}^{*}\right]$, where $T C T_{6 i}^{*}, T C T_{7 i}^{*}$ and $T C T_{8 i}^{*}$ are the optimal values obtained from the solution to problems $P_{6}, P_{7}$, and $P_{8}$ respectively.

Since only one production cycle and only one set-up is involved, there can be no reduction in set-up cost due to learning effects under this policy. The result of using this policy as shown in Table 3 indicates that the total relevant cost of the system is higher than that obtained under the previous policies (VDP and SDP) even when the effect of reduction in set-up cost is not considered. When the learning index is zero, VDP, SDP and SPC policies gives total relevant system cost of $\$ 15780.65$, $\$ 15870.60$, and $\$ 17873.70$, respectively. This shows that the single period policy is more expensive than the multi-period policies. When the effect of reduction in set-up cost due to learning is considered, the gap between the costs of single period policy and the multi-period policies further widens. This shows the importance of using a multi-period production strategy that involves small, frequent and short run production lots when dealing with deteriorating seasonal items with a variable demand pattern. This is more economical and enables a faster response to customers' demand than producing once to meet the entire demand of the season. 
Table 3

Optimal results using the SPC policy

\begin{tabular}{ccccccc}
\hline$n$ & $t_{i-1}^{*}$ & $s_{i}^{*}$ & $t_{i}^{*}$ & $T C T_{i}^{*}$ & $T_{i}^{*}$ & $T C T_{i}^{*} * T_{i}^{*}$ \\
\hline 1 & 0 & 8.2796 & 13 & 1374.9 & 13 & 17873.7 \\
\hline \multicolumn{6}{c}{ Total relevant cost for the season } \\
\hline
\end{tabular}

\subsection{Sensitivity of model to other cost parameters}

We examine the sensitivity of the developed model to other cost parameters different from the set-up cost using the VDP policy. This is done by varying the values of the inventory holding cost per unit $\left(C_{H}\right)$ and the production cost per unit $\left(C_{P}\right)$ by $+50 \%,+25 \%,-25 \%,-50 \%$, taking one at a time while others were kept constant.

Table 4

Sensitivity of model to production $\operatorname{cost}\left(C_{P}\right)$ using VDP policy $(c=0.5)$

\begin{tabular}{|c|c|c|c|c|c|c|c|}
\hline & $n$ & $t_{i-1}^{*}$ & $s_{i}^{*}$ & $t_{i}^{*}$ & $T C T_{i}^{*}$ & $T_{i}^{*}$ & $T C T_{i}^{*} * T_{i}^{*}$ \\
\hline \multirow{4}{*}{$C_{P}=5$} & 1 & 0 & 2.4768 & 3.1539 & 792.86 & 3.1539 & 2500.60 \\
\hline & 2 & 3.1539 & 4.5073 & 5.1182 & 816.72 & 1.9643 & 1604.28 \\
\hline & 3 & 5.1182 & 6.4005 & 6.9649 & 814.02 & 1.8467 & 1503.25 \\
\hline & 4 & 6.9649 & 10.0195 & 13.0000 & 544.43 & 6.0351 & 3285.69 \\
\hline \multicolumn{7}{|c|}{ Total relevant cost for the season } & 8893.82 \\
\hline \multirow{4}{*}{$C_{P}=7.5$} & 1 & 0 & 2.563 & 3.2752 & 1105.30 & 3.2752 & 3620.08 \\
\hline & 2 & 3.2752 & 4.5678 & 5.1529 & 1125.90 & 1.8777 & 2114.10 \\
\hline & 3 & 5.1529 & 6.3715 & 6.9093 & 1126.50 & 1.7564 & 1978.58 \\
\hline & 4 & 6.9093 & 9.9991 & 13.0000 & 750.54 & 6.0907 & 4571.31 \\
\hline \multicolumn{7}{|c|}{ Total relevant cost for the season } & 12284.07 \\
\hline \multirow{4}{*}{$C_{P}=10$} & 1 & 0 & 2.6231 & 3.3596 & 1417.43 & 3.3596 & 4762.00 \\
\hline & 2 & 3.3596 & 4.6008 & 5.1638 & 1435.20 & 1.8042 & 2589.39 \\
\hline & 3 & 5.1638 & 6.3278 & 6.8428 & 1438.60 & 1.6790 & 2415.41 \\
\hline & 4 & 6.8428 & 9.9749 & 13.0000 & 960.31 & 6.1572 & 5912.82 \\
\hline \multicolumn{7}{|c|}{ Total relevant cost for the season } & 15679.62 \\
\hline \multirow{4}{*}{$C_{P}=12.5$} & 1 & 0 & 2.6675 & 3.4218 & 1729.40 & 3.4218 & 5917.66 \\
\hline & 2 & 3.4218 & 4.6182 & 5.1619 & 1744.50 & 1.7401 & 3035.60 \\
\hline & 3 & 5.1619 & 6.2785 & 6.7737 & 1750.50 & 1.6118 & 2821.46 \\
\hline & 4 & 6.7737 & 9.9498 & 13.0000 & 1173.20 & 6.2263 & 7304.70 \\
\hline \multicolumn{7}{|c|}{ Total relevant cost for the season } & 19079.42 \\
\hline \multirow{4}{*}{$C_{P}=15$} & 1 & 0 & 2.7016 & 3.4694 & 2041.10 & 3.4694 & 7081.39 \\
\hline & 2 & 3.4694 & 4.626 & 5.1524 & 2053.70 & 1.6830 & 3456.38 \\
\hline & 3 & 5.1524 & 6.2274 & 6.7053 & 2062.00 & 1.5529 & 3202.08 \\
\hline & 4 & 6.7053 & 9.9251 & 13.0000 & 1388.90 & 6.2947 & 8742.71 \\
\hline \multicolumn{7}{|c|}{ Total relevant cost for the season } & 22482.56 \\
\hline
\end{tabular}

The results of these analyses are presented in Table 4 and Table 5. Table 4 shows that the total relevant cost is highly sensitive to the changes in the value of production cost per unit $\left(C_{P}\right)$. It increases with increase in $C_{P}$ and vice versa. The number of lots produced is, however, less sensitive to changes in $C_{P}$. On the other hand, Table 5 shows that the total relevant cost is less sensitive to changes in the value of inventory holding cost per unit $\left(C_{H}\right)$ while the number of lots produced is highly sensitive to changes in $C_{H}$. This in agreement with real-world inventory management practise wherein high inventory holding costs motivates increase in the production frequency so as to reduce 
number of items to be held in inventory at any particular time. One of the major advantages of the just-in-time (JIT) policy is to reduce the amount spent in holding items in inventory to the minimum. These analyses showed that the model developed in this paper encourages higher production frequency whenever there is an increase in inventory holding cost but discourages increase in production frequency when there is an increase in production cost per unit of item. The implication of this is that the effect of the increases in costs on the total relevant cost of the system cost will be minimized and this is one of the advantages of the VDP policy.

Table 5

Sensitivity of model to inventory holding $\operatorname{cost}\left(C_{H}\right)$ using VDP policy $(\mathrm{c}=0.5)$

\begin{tabular}{|c|c|c|c|c|c|c|c|}
\hline & $n$ & $t_{i-1}^{*}$ & $s_{i}^{*}$ & $t_{i}^{*}$ & $T C T_{i}^{*}$ & $T_{i}^{*}$ & $T C T_{i}^{*} * T_{i}^{*}$ \\
\hline \multirow{4}{*}{$C_{H}=0.75$} & 1 & 0.0000 & 2.9387 & 3.7991 & 1359.50 & 3.7991 & 5164.88 \\
\hline & 2 & 3.7991 & 5.3786 & 6.0821 & 1376.80 & 2.2830 & 3143.23 \\
\hline & 3 & 6.0821 & 8.0000 & 8.8636 & 1382.30 & 2.7815 & 3844.87 \\
\hline & 4 & 8.8636 & 10.7351 & 13.0000 & 635.64 & 4.1364 & 2629.25 \\
\hline \multicolumn{7}{|c|}{ Total relevant cost for the season } & 14782.23 \\
\hline \multirow{4}{*}{$C_{H}=1.125$} & 1 & 0 & 2.7667 & 3.5603 & 1389.30 & 3.5603 & 4946.32 \\
\hline & 2 & 3.5603 & 4.9513 & 5.578 & 1407.20 & 2.0177 & 2839.31 \\
\hline & 3 & 5.578 & 6.855 & 7.412 & 1410.40 & 1.8340 & 2586.67 \\
\hline & 4 & 7.412 & 10.1865 & 13.0000 & 863.66 & 5.5880 & 4826.13 \\
\hline \multicolumn{7}{|c|}{ Total relevant cost for the season } & 15198.43 \\
\hline \multirow{4}{*}{$C_{H}=1.5$} & 1 & 0 & 2.6231 & 3.3596 & 1417.43 & 3.3596 & 4762.00 \\
\hline & 2 & 3.3596 & 4.6008 & 5.1638 & 1435.20 & 1.8042 & 2589.39 \\
\hline & 3 & 5.1638 & 6.3278 & 6.8428 & 1438.60 & 1.6790 & 2415.41 \\
\hline & 4 & 6.8428 & 9.9749 & 13.0000 & 960.31 & 6.1572 & 5912.82 \\
\hline \multicolumn{7}{|c|}{ Total relevant cost for the season } & 15679.62 \\
\hline \multirow{5}{*}{$C_{H}=1.875$} & 1 & 0 & 2.5010 & 3.1879 & 1444.30 & 3.1879 & 4604.28 \\
\hline & 2 & 3.1879 & 4.3075 & 4.8168 & 1461.10 & 1.6289 & 2379.99 \\
\hline & 3 & 4.8168 & 5.8906 & 6.3711 & 1466.60 & 1.5543 & 2279.54 \\
\hline & 4 & 6.3711 & 7.3838 & 7.8245 & 1465.50 & 1.4534 & 2129.96 \\
\hline & 5 & 7.8245 & 10.3456 & 13.0000 & 859.53 & 5.1755 & 4448.51 \\
\hline \multicolumn{7}{|c|}{ Total relevant cost for the season } & 15842.28 \\
\hline \multirow{5}{*}{$C_{H}=2.25$} & 1 & 0 & 2.3954 & 3.0389 & 1470.00 & 3.0389 & 4467.18 \\
\hline & 2 & 3.0389 & 4.0578 & 4.5215 & 1485.50 & 1.4826 & 2202.40 \\
\hline & 3 & 4.5215 & 5.5218 & 5.9736 & 1494.20 & 1.4521 & 2169.73 \\
\hline & 4 & 5.9736 & 6.916 & 7.3312 & 1491.50 & 1.3576 & 2024.86 \\
\hline & 5 & 7.3312 & 10.1559 & 13.0000 & 958.97 & 5.6688 & 5436.21 \\
\hline \multicolumn{7}{|c|}{ Total relevant cost for the season } & 16300.38 \\
\hline
\end{tabular}

\section{Conclusions}

In this paper, we have considered the multi-period production lot sizing problem that involves deteriorating seasonal products with a three-phase ramp-type demand pattern. The study also included the effects of learning in set-up on the production and inventory schedules and costs. Two different production strategies (VDP and SDP policies) that can ensure a fast-response to customers' demand were presented. These strategies were compared with the common single production cycle (SPC) strategy usually adopted in most production-inventory models. Through numerical examples, we showed that the total relevant cost of a production-inventory system is the highest when there is no improvement and no reduction in set-up cost due to learning. 
It was equally shown that the learning-based reduction in set-up costs led to higher production frequency and shorter production runs which are vital aspects of the just-in-time (JIT) philosophy. Comparison between the VDP and SDP policies showed the importance of allowing for changes in the demand pattern within production/replenishment cycles whenever such changes occur. It was shown that neglecting such changes usually lead to overall increase in the total relevant cost of the production-inventory system. A multi-period production strategy that involves small, frequent and short-run production lots was also shown to be economically better than the single period strategy when dealing with deteriorating seasonal items with a varying demand pattern. The study showed that the gap between the cost of a single period production policy and that of a multi-period production policy is further widened when the effect of the reduction in set-up cost due to learning is considered. The sensitivity analysis showed that the model generated higher number of production lots at higher values of inventory holding cost thereby minimizing its effect on total relevant cost. The number of lots produced by the model is, however, less sensitive to changes in production cost per unit of item. This study can be extended by considering the effect of learning and forgetting on set-up, production rate and product quality for seasonal product with a ramp-type demand pattern.

\section{References}

Abdul, I. \& Murata, A. (2011). An inventory model for deteriorating items with varying demand pattern and unknown time horizon. International Journal of Industrial Engineering Computations, 2, 81-86.

Adler, G. L. \& Nanda, R. (1974). The effects of learning on optimal lot size determination-multiple product case. AIIE Transactions, 6, 21-27.

Alamri, A. A. \& Balkhi, Z. T. (2007). The effects of learning and forgetting on the optimal production lot size for deteriorating items with time varying demand and deterioration rates. International Journal of Production Economics, 107 (1), 125-138.

Andijani, A. (1998). Set-up cost reduction in a multi-stage order quantity model. Production Planning and Control, 9, 121-126.

Balkhi, Z. T. (2003). The effects of learning on the optimal production lot size for deteriorating and partially backordered items with time varying demand and deterioration rates. Applied Mathematical Modelling, 27 (10), 763-779.

Chand, S. (1989). Lot sizes and set-up frequency with learning and process quality. European Journal of Operational Research, 42, 190-202.

Cheng, M. \& Wang, G. (2009). A note on the inventory model for deteriorating items with trapezoidal type demand rate. Computers \& Industrial Engineering, 56, 1296-1300.

Cheng, T. C. E. (1994). An economic manufacturing quantity model with learning effects. International Journal of Production Economics, 33, 257-264.

Chiu, H. N., Chen, H. M. \& Weng, L. C.(2003). Deterministic time-varying demand lot-sizing models with learning and forgetting in set-ups and production. Production and Operations Management, 12 (1), 120-127.

Darwish, M. A. (2008). EPQ models with varying set-up cost. International Journal Production Economics, 113, 297-306.

Das, D., Roy, A. \& Kar, S. (2011). A Production-Inventory Model for a Deteriorating Item Incorporating Learning Effect Using Genetic Algorithm. Advances in Operations Research Volume 2010, Article ID 146042, 26 pages, doi:10.1155/2010/146042.

Dobos, I. \& Richter, K. (2003). A production/recycling model with stationary demand and return rates. Central European Journal of Operations Research, 11 (1), 35-46.

Dobos, I. \& Richter, K. (2004). An extended production/recycling model with stationary demand and return rates. International Journal of Production Economics, 90 (3), 311-323. 
Fisk, J. C. \& Ballou, D. B. (1982). Production lot sizing under a learning sect. AIIE Transactions, 14, 257-264.

Gulledge, T. R. \& Khoshnevis, B. (1987). Production rate, learning, and program costs: Survey and Bibliography. Engineering Costs and Production Economics, 11, 223-236.

Hill, R. M. (1995). Inventory model for increasing demand followed by level demand. Journal of the Operational Research Society, 46, 1250-1259.

Jaber, M. Y., \& Bonney, M. (1999). The economic manufacture/order quantity (EMQ/ EOQ) and the learning curve: past, present, and future. International Journal of Production Economics, 59, 93102.

Jaber, M. Y., \& Bonney, M. (2003). Lot sizing with learning and forgetting in set-ups and in product quality. International Journal of Production Economics, 83 (1), 95-111.

Jaber, M. Y., \& Bonney, M. C. (1996). Production breaks and the learning curve: the forgetting phenomena. Applied Mathematical Modelling, 20 (2), 162-169.

Jaber, M. Y., \& Bonney, M. C. (1997). A comparative study of learning curves with forgetting. Applied Mathematical Modelling, 21 (8), 523-531.

Jaber, M. Y., Bonney, M. \& Guiffrida, A. (2010) Coordinating a three-level supply chain with learning-based continuous improvement. International Journal of Production Economics, 127, 27 38.

Jaber, M. Y., \& El Saadany M. A. (2011). An economic production and remanufacturing model with learning effects. International Journal Production Economics, 131, 115-127.

Jaber, M. Y., \& Sikström, S. (2004). A numerical comparison of three potential learning and forgetting models. International Journal of Production Economics, 92(3), 281-294.

Karwan, K., Mazzola, J. \& Morey, R. (1988). Production lot sizing under set-up and worker learning. Naval Research Logistics, 35, 159-179.

Keachie, E. C., \& Fontana, R. J. (1966). Effects of learning on optimal lot size. Management Science,13(2), 102-108.

Manna, S. K., \& Chaudhuri, K. S. (2006). An EOQ model with ramp-type demand rate, time dependent deterioration rate, unit production cost and shortages. European Journal of Operational Research, 171, 557-566.

Manna, S. K., \& Chiang, C. (2010). Economic production quantity models for deteriorating items with ramp-type demand, International Journal of Operational Research, 7, 429-444.

Paknejad, M., Nasri, F. \& Affisco, J. F. (1996). Analysis of set-up cost reduction in a two-stage system with power investment function. ZOR/Mathematical Methods of Operations Research, 43, 389-401.

Panda, S., Saha, S. \& Basu, M. (2009). Optimal production stopping time for perishable products with ramp-type quadratic demand dependent production and set-up cost, Central European Journal of Operational Research, 17, 381-396.

Panda, S., Senapati, S. \& Basu, M. (2008). Optimal replenishment policy for perishable seasonal products in a season with ramp-type time dependent demand. Computers and Industrial Engineering, 54, 301-314.

Porteus, E. (1985). Investing in reduced set-ups in the EOQ model. Management Science, 31, 9981010.

Rachamadugu, R. \& Schriber, T. J. (1995). Optimal and heuristic policies for lot sizing with learning in set-ups. Journal of Operations Management, 13, 229-245.

Replogle, S. (1988). The strategic use of smaller lot sizes through a new EOQ model, Production and Inventory Management, 41-44.

Salameh, M. K., Abdul-Malak, M. U. \& Jaber, M. Y. (1993). Mathematical modelling of the effect of human learning in the finite production inventory model. Applied Mathematical Modelling Journal, 17, 613-615.

Schonberger, R. (1982). Japanese Manufacturing Technologies, The Free Press, New York.

Şen, A. (2008). The US fashion industry: A supply chain review. International Journal of Production Economics, 114, 571-593. 
Steedman, I. (1970). Some improvement curve theory. International Journal of Production Research, 8, 189-205.

Wright, T. (1936). Factors affecting the cost of airplanes, Journal of Aeronautical Science, 3, 122128. 